\title{
Formulation and Development of Taste Masked Orally Disintegrating Tablets of Perindopril Erbumine by Direct Compression Method
} Mukesh P Ratnaparkhi*

Marathwada Mitra Mandal's College of Pharmacy, Thergaon, Pune-411033, India

\begin{abstract}
The aim of current study was to formulate and evaluate taste masked orally disintegrating tablets of Perindopril Erbumine. Taste masking was done by using Eudragit E 100 in the ratio of 1:3 (drug:polymer) by mass extrusion method. The preliminary batches were prepared by using different superdisintegrants like Ac-Di-Sol, Primogel, Tulsion-335 and Tulsion-339. From the preliminary study it was found that orodispersible tablets containing Ac-DiSol showed better disintegration time and it was considered for further studies. A $3^{2}$ full factorial design was applied to optimize the formulations, nine batches were prepared and evaluated. It was observed from the evaluations that the batch $\mathrm{A}_{2}$ showed the best disintegration time and also completes drug release within five minutes. Hence it was concluded that orally disintegrating tablets of Perindopril Erbumine can be successfully formulated using Ac-Di-Sol.
\end{abstract}

Keywords: Perindopril erbumine; Taste masking; Ac-Di-Sol; Avicel PH101; $3^{2}$ full factorial design

\section{Introduction}

Although various novel and advanced drug delivery systems have been introduced for therapeutic use, the popularity of oral dosage forms, particularly tablets have not been eclipsed, because tablets still have numerous advantages, besides others an economical production. However, one important drawback of tablets as a dosage form is the need to swallow. Dysphasia or general difficulties in swallowing of tablets may be a problem for geriatric, paediatric, or travelling patients, if the latter do not have access to water. Dysphasia is also pertinent with the number of medical conditions including strokes, Parkinson's disease, AIDS, thyroidectomy, head and neck radiation therapy and other neurological disorders including cerebral palsy hence resulting in higher incidence of non-compliance and ineffective therapy. Thus, the orally disintegrating drug delivery system (DDS) is fast dissolving / dispersing, and dissolves in the patient's mouth within a matter of seconds without need of water or chewing. It may therefore be the best solution for patient suffering from dysphasia.

Perindopril ter-butyl amine belongs to a group called Angiotensin Converting Enzyme (ACE) inhibitors [1]. Inhibition of ACE results in decreased plasma Angiotensin II, leading to decreased vasoconstriction, increased plasma rennin activity and decreased aldosterone secretion. The overall effect of this is a drop in blood pressure and a decrease in the workload of the heart. Perindopril tert-butyl amine is a pro-drug that is hydrolyzed by esterases to the active metabolite Perindoprilat. Perindopril is rapidly absorbed, reaching peak plasma concentration about 1 hour after a single oral dose. Perindoprilat reaches peak plasma concentrations in 2 to 6 hours. The bioavailability of Perindopril is about $70 \%$. The presence of food does not affect the rate and extent of absorption of Perindopril; however, food reduces the conversion of Perindopril to Perindoprilat [2,3].

Therefore, the purpose of the present study was to develop a fast disintegrating tablet of Perindopril Erbumine by direct compression and to mask the bitter taste of Perindopril. Such tablet should disintegrate rapidly in the saliva without need of water and release the drug instantly for immediate therapeutic effect, and be of acceptable taste.

\section{Material and Method}

Perindopril Erbumine was generously gifted by Hetero drugs Pvt Ltd, Eudragit E100 was gifted by Evonick (Mumbai). Primogel, Ac-DiSol and Avicel (PH101) were procured from Maple Biotech Pvt Ltd, Tulsion 335 and Tulsion 339 were obtained from Thermax India Pvt Ltd. Manitol was obtained from Oswal chemicals. All other chemicals used were of analytical grade.

\section{Determination of taste threshold value of bitterness for Perindopril Erbumine}

The minimum concentration among a range of dilutions of a substance at which the volunteer just starts feeling the bitter taste is known as taste threshold concentration. The threshold bitterness concentration of Perindopril Erbumine was determined by a panel of 12 healthy human volunteers from whome the written consent were taken. The design of the experiment is shown in table 1. Different

\begin{tabular}{|l|l|l|l|l|l|l|}
\hline Sr no & Concentration $\boldsymbol{\mu g} / \mathbf{m l}$ & $\mathbf{0}$ & $\mathbf{1}$ & $\mathbf{2}$ & $\mathbf{3}$ & $\mathbf{4}$ \\
\hline 1 & 10 & & & & & \\
\hline 2 & 50 & & & & & \\
\hline 3 & 100 & & 12 & & & \\
\hline 4 & 110 & & & 3 & & \\
\hline 5 & 120 & & 9 & & \\
\hline 6 & 130 & & & & 12 & \\
\hline 7 & 140 & & & 12 & \\
\hline 8 & 150 & & & & 12 \\
\hline $0=$ sweet, $1=$ acceptable, 2=slightly bitter, 3= bitter, 4=intensely bitter.
\end{tabular}

Table 1: Determination of taste threshold value of bitterness of perindopril erbumine.

*Corresponding author: Mukesh P. Ratnaparkhi, Marathwada Mitra Mandal's College of Pharmacy, Thergaon, Pune-411033, India, E-mail: alimohammadi@ tums.ac.ir

Received June 20, 2012; Accepted July 18, 2012; Published July 22, 2012

Citation: Ratnaparkhi MP (2012) Formulation and Development of Taste Masked Orally Disintegrating Tablets of Perindopril Erbumine by Direct Compression Method. Pharmaceut Anal Acta 3:162. doi:10.4172/2153-2435.1000162

Copyright: (C) 2012 Ratnaparkhi MP. This is an open-access article distributed under the terms of the Creative Commons Attribution License, which permits unrestricted use, distribution, and reproduction in any medium, provided the original author and source are credited. 
Citation: Ratnaparkhi MP (2012) Formulation and Development of Taste Masked Orally Disintegrating Tablets of Perindopril Erbumine by Direct Compression Method. Pharmaceut Anal Acta 3:162. doi:10.4172/2153-2435.1000162

Page 2 of 10

concentrations of the drug sample ranging from $10 \mu \mathrm{g} / \mathrm{ml}$ to $150 \mu \mathrm{g} /$ $\mathrm{ml}$ were prepared in phosphate buffer $\mathrm{pH}$ 6.8. The volunteers were administered with $10 \mathrm{ml}$ of the test samples one at a time with an interval of ten minutes. The volunteers were told to keep the test solution in mouth for 30 seconds and later spit it out. The taste observed by the volunteers for each test sample was recorded. It was observed that 9 out of 12 volunteers felt bitterness after 30 seconds at concentration of $120 \mu \mathrm{g} / \mathrm{ml}$ and three volunteers observed the bitter taste at $110 \mu \mathrm{g} / \mathrm{ml}$. Therefore the concentration of $110 \mu \mathrm{g} / \mathrm{ml}$ was considered as the taste threshold concentration of Perindopril Erbumine [4-6].

\section{Preparation of the taste masked granules}

Physical mixtures of Perindopril Erbumine: Eudragit E 100 was prepared in various ratios from 1:1 to 1:7. The recommended solvent for Eudragit E 100 is ethanol and water respectively. A gel containing Perindopril erbumine and Eudragit E 100 was prepared by the following method. Perindopril erbumine was mixed with different amount of powdered Eudragit E100 then 10\% ethanol was added to this mixture in a glass beaker and gel was prepared using a mechanical stirrer. The gel was manually extrudated through a syringe. The ethanol was evaporated, by keeping the extrudates overnight at room temperature. The solidified gel in the shape of strings was crushed and sieved through a sieve sized $255 \mu \mathrm{m}$ to make the granules [7-9].

\section{In-vitro Taste evaluation}

The in-vitro taste evaluation was carried out to determine the drug release from the taste masked granules at the salivary $\mathrm{pH}$ [9-12]. It was determined by placing Perindopril Erbumine: Eudragit E100 complex equivalent to $4 \mathrm{mg}$ of Perindopril Erbumine in $10 \mathrm{ml}$ of phosphate buffer and shaken for 30 seconds. The amount of drug released was then analysed at $215 \mathrm{~nm}$. The results of analysis are shown in table 2.
The prepared granules were subjected to thermal analysis, FTIR, $\mathrm{X}$-Ray diffraction (XRD) studies.

\section{Thermal analysis}

Differential scanning calorimetry (DSC) was performed using a Mettler TA 823 apparatus. The drug, the polymer, and the drug-polymer complex were subjected to the DSC study. Samples were heated at a scanning rate of $20 \mathrm{~K} / \mathrm{min}$ from $40^{\circ} \mathrm{C}$ to $300^{\circ} \mathrm{C}$ under nitrogen.

\section{Fourier Transform Infrared Spectroscopy (FTIR)}

The drug, polymer and drug polymer complex were subjected to IR spectroscopy to check the drug polymer Interaction using FT-IR (SHIMADZU $8400 \mathrm{~S}$ ) and the KBr disk method.

\section{$\mathrm{X}$-ray diffraction (XRD) studies}

X-Ray Diffraction analysis was carried out to evaluate the degree of crystallinity. The pure perindopril erbumine, pure Eudragit E 100, and the perindopril-erbumine-Eudragit E 100 complex (1:3) were subjected to powder XRD at 2 angles between $5^{\circ}$ and $50^{\circ}$ in increments of $0.4^{\circ}$.

\section{Preparation of preliminary batches of fast disintegrating tablets of Perindopril Erbumine}

For the preliminary batches, Drug-Eudragit complex, Mannitol, Avicel (pH101), Superdisintegrants, Talc and Magnesium sterate were used. Mannitol was used as filler and also to impart cooling sensation in mouth. Avicel (pH101) was used as a binder because of its binding property. The concentration of Superdisintegrants such as Ac-Di-Sol, Primojel', Tulsion 335 and Tulsion 339 was between 2-5\%. A control formulation was made without a disintegrant. All ingredients were

\begin{tabular}{|c|c|c|c|}
\hline Taste threshold value & Absorbance noted & Drug:eudragit complex & $\begin{array}{l}\% \text { drug released in relation to taste } \\
\text { threshold value }\end{array}$ \\
\hline & & $1: 1$ & $234.35 \%$ \\
\hline & & $1: 2$ & $121.80 \%$ \\
\hline & & $1: 3$ & $84.71 \%$ \\
\hline \multirow[t]{4}{*}{$100 \mu \mathrm{g} / \mathrm{ml}$} & 1.243 & $1: 4$ & $64.11 \%$ \\
\hline & & $1: 5$ & $55.51 \%$ \\
\hline & & $1: 6$ & $49.39 \%$ \\
\hline & & $1: 7$ & $33.18 \%$ \\
\hline
\end{tabular}

Table 2: Uv method for determination of the ratio for drug eudragit complex for taste masking

\begin{tabular}{|c|c|c|c|c|c|c|c|c|c|c|c|c|}
\hline Ingredients & $\begin{array}{l}F_{1} \\
(\mathbf{m g})\end{array}$ & $\begin{array}{l}F_{2} \\
\text { (mg) }\end{array}$ & $\begin{array}{l}F_{3} \\
(\mathbf{m g})\end{array}$ & $\begin{array}{l}F_{4} \\
(\mathbf{m g})\end{array}$ & $\begin{array}{l}F_{5} \\
(\mathbf{m g})\end{array}$ & $\begin{array}{l}F_{6} \\
(\mathbf{m g})\end{array}$ & $\begin{array}{l}F_{7} \\
(\mathrm{mg})\end{array}$ & $\begin{array}{l}F_{8} \\
(\mathbf{m g})\end{array}$ & $\begin{array}{l}F_{9} \\
(\mathbf{m g})\end{array}$ & $\begin{array}{l}F_{10} \\
(\mathbf{m g})\end{array}$ & $\begin{array}{l}F_{11} \\
(\mathrm{mg})\end{array}$ & $\begin{array}{l}F_{12} \\
(\mathrm{mg})\end{array}$ \\
\hline $\begin{array}{l}\text { Drug: } \\
\text { Polymer complex }\end{array}$ & 12 & 12 & 12 & 12 & 12 & 12 & 12 & 12 & 12 & 12 & 12 & 12 \\
\hline Mannitol & 129 & 127 & 124 & 129 & 127 & 124 & 129 & 127 & 124 & 129 & 127 & 124 \\
\hline Avicel & 50 & 50 & 50 & 50 & 50 & 50 & 50 & 50 & 50 & 50 & 50 & 50 \\
\hline Ac-di-sol & 5 & 7 & 10 & & & & & & & & & \\
\hline Primogel & & & & 5 & 7 & 10 & & & & & & \\
\hline Tulsion335 & & & & & & & 5 & 7 & 10 & & & \\
\hline Tulsion339 & & & & & & & & & & 5 & 7 & 10 \\
\hline Mag-stearate & 2 & 2 & 2 & 2 & 2 & 2 & 2 & 2 & 2 & 2 & 2 & 2 \\
\hline Talc & 2 & 2 & 2 & 2 & 2 & 2 & 2 & 2 & 2 & 2 & 2 & 2 \\
\hline Total weight & 200 & 200 & 200 & 200 & 200 & 200 & 200 & 200 & 200 & 200 & 200 & 200 \\
\hline
\end{tabular}

Table 3: Formulation of preliminary batches of fast disintegrating tablets of perindopril erbumine. 
Citation: Ratnaparkhi MP (2012) Formulation and Development of Taste Masked Orally Disintegrating Tablets of Perindopril Erbumine by Direct Compression Method. Pharmaceut Anal Acta 3:162. doi:10.4172/2153-2435.1000162

Page 3 of 10

passed through mesh $250 \mu \mathrm{m}$. The ingredients were mixed according to table 3. Magnesium stearate and talc were added in a final step and mixed, this blend was subjected to analysis of pre-compression parameters which included Angle of repose, Bulk density, Tap density, Carr's index and Hausner's ratio [13,14]. The Blend was compressed on $8 \mathrm{~mm}$ (diameter) flat punches on a 'Rimek mini press 16 station rotary compression machine. Each tablet weighing $200 \mathrm{mg}$ corresponding to $4 \mathrm{mg}$ of perindopril erbumine were obtained.

The tablets were evaluated for weight variation, thickness, friability, hardness and in-vitro disintegration time. In-vitro dissolution time was not evaluated for preliminary batches as improvement in disintegration time was of prime importance for this study.

\section{Full factorial design}

A $3^{2}$ randomized full factorial design was adopted to optimize the variables. In this design 2 factors were evaluated, each at 3 levels, and experimental trials were performed at all 9 possible combinations [1518]. Layout of full factorial design is shown in table 4. The amounts of binder, Avicel pH101 $\left(\mathrm{X}_{1}\right)$ and the amount of Ac-Di-Sol $\left(\mathrm{X}_{2}\right)$ were selected as independent variables precompression parameters were evaluated and the observations are shown in table 5 . The batches were formulated according to the formula given in table 6 . The optimized batches were evaluated for content uniformity, disintegration time, wetting time, water absorption ratio and \% drug release in 5 minutes $\left(\mathrm{Q}_{\mathrm{T} 5}\right)$ Batches of factorial design is shown in table 7.

\section{Precompression parameters}

Angle of repose $(\theta)$ : Angle of repose is defined as the maximum angle possible between the surface of a pile of the Powder and horizontal plane. The frictional force in a loose powder or granules can be measured by angle of repose.

$\tan \theta=\mathrm{h} / \mathrm{r}$

$\theta=\tan -1(\mathrm{~h} / \mathrm{r})$

Where, $\theta$ is the angle of repose

\begin{tabular}{|l|l|l|}
\hline Batch code & $\mathbf{X}_{1}$ & $\mathbf{X}_{2}$ \\
\hline $\mathbf{A}_{\mathbf{1}}$ & -1 & -1 \\
\hline $\mathbf{A}_{2}$ & -1 & 0 \\
\hline $\mathbf{A}_{3}$ & -1 & 1 \\
\hline $\mathbf{A}_{\mathbf{4}}$ & 0 & -1 \\
\hline $\mathbf{A}_{5}$ & 0 & 0 \\
\hline $\mathbf{A}_{6}$ & 0 & 1 \\
\hline $\mathbf{A}_{\mathbf{7}}$ & 1 & -1 \\
\hline $\mathbf{A}_{8}$ & 1 & 0 \\
\hline $\mathbf{A}_{9}$ & 1 & 1 \\
\hline Coded values & Amount of binder (AvicelPH101) $\mathbf{X}_{1}$ & $\mathbf{A m o u n t}$ of superdisintegrant (Ac-Di-Sol) $\mathbf{X}_{2}$ \\
\hline-1 & $30 \mathrm{mg}$ & $5 \mathrm{mg}$ \\
\hline 0 & $50 \mathrm{mg}$ & $7.5 \mathrm{mg}$ \\
\hline 1 & $70 \mathrm{mg}$ & $10 \mathrm{mg}$ \\
\hline
\end{tabular}

Table 4: Full $3^{2}$ factorial layout.

\begin{tabular}{|l|l|l|l|l|l|l|}
\hline Sr.no & Formulation & Angle of repose & Bulk density & Tap density & Carr's index \\
\hline 1 & $\mathrm{~A}_{1}$ & 25.27 & 0.55 & 0.58 & 12.00 \\
\hline 2 & $\mathrm{~A}_{2}$ & 25.94 & 0.5 & 0.58 & 1.13 \\
\hline 3 & $\mathrm{~A}_{3}$ & 25.27 & 0.58 & 0.62 & 1.16 \\
\hline 4 & $\mathrm{~A}_{4}$ & 23.19 & 0.52 & 0.66 & 1.79 \\
\hline 5 & $\mathrm{~A}_{5}$ & 24.10 & 0.5 & 0.62 & 10.34 \\
\hline 6 & $\mathrm{~A}_{6}$ & 24.77 & 0.5 & 0.6 & 13.79 \\
\hline 7 & $\mathrm{~A}_{7}$ & 27.82 & 0.52 & 0.58 & 1.16 \\
\hline 8 & $\mathrm{~A}_{8}$ & 27.25 & 0.55 & 0.55 & 1.25 \\
\hline 9 & $\mathrm{~A}_{9}$ & 27.89 & 0.5 & 0.58 & 1.20 \\
\hline
\end{tabular}

Table 5: Evaluation of precompression parameters of optimization batches.

\begin{tabular}{|c|c|c|c|c|c|c|c|c|c|c|}
\hline Ingredients & $\begin{array}{l}A_{1} \\
(m g)\end{array}$ & $\begin{array}{l}A_{2} \\
\text { (mg) }\end{array}$ & $\begin{array}{l}A_{3} \\
\text { (mg) }\end{array}$ & $\begin{array}{l}A_{4} \\
(\mathrm{mg})\end{array}$ & $\begin{array}{l}A_{5} \\
(\mathrm{mg})\end{array}$ & $\begin{array}{l}A_{6} \\
\text { (mg) }\end{array}$ & $\begin{array}{l}A_{7} \\
\text { (mg) }\end{array}$ & $\begin{array}{l}A_{8} \\
\text { (mg) }\end{array}$ & $\begin{array}{l}A_{9} \\
\text { (mg) }\end{array}$ & Control \\
\hline $\begin{array}{l}\text { Drug: } \\
\text { Polymer complex }\end{array}$ & 12 & 12 & 12 & 12 & 12 & 12 & 12 & 12 & 12 & 12 \\
\hline Mannitol & 149 & 147 & 144 & 129 & 127 & 124 & 109 & 107 & 104 & 134 \\
\hline Avicel (PH101) & 30 & 30 & 30 & 50 & 50 & 50 & 70 & 70 & 70 & 50 \\
\hline Ac-di-sol & 5 & 7 & 10 & 5 & 7 & 10 & 5 & 7 & 10 & \\
\hline Mag-stearate & 2 & 2 & 2 & 2 & 2 & 2 & 2 & 2 & 2 & 2 \\
\hline Talc & 2 & 2 & 2 & 2 & 2 & 2 & 2 & 2 & 2 & 2 \\
\hline Total weight & 200 & 200 & 200 & 200 & 200 & 200 & 200 & 200 & 200 & 200 \\
\hline
\end{tabular}

Table 6: Formulation using $3^{2}$ full factorial design. 
$\mathrm{h}$ is height of pile

$r$ is radius of the base of pile

Bulk density: Bulk density is defined as the mass of a powder divided by the bulk volume. The bulk density of a powder depends primarily on particle size distribution, particle shape, and the tendency of the particles to adhere to one another.

$\mathrm{LBD}=$ Weight of the powder

Volume of the packing

$\mathrm{TBD}=$ Weight of the powder -

Tapped volume of packing

Carr's compressibility index: The compressibility index of the granules was determined by Carr's compressibility index.

Carr's Index (\%)=TBD - LBD/TBD x 100 ----- (c)

Hausners ratio: It is determined by comparing tapped density to the bulk density by using following equation

Hausners ratio=tapped density / bulk deksity.

The results of the powder flow properties determination are summarised in table 7 .

\section{Evaluation of tablet properties}

Weight variation: The test was performed according to specifications given in the Ph. Eur., 2004 on 20 tablets. The maximum acceptable limit is $\pm 7.5 \%$ deviation of an individual mass from average mass [19].

Measurement of tablet friability: Tablet friability was measured using the Roche Friabilator according to Ph. Eur, on ten tablets each [20]. The friability was determined as the mass loss in percent according to Equation.

$\mathrm{F}=\mathrm{W}_{\mathrm{A}}-\mathrm{W}_{\mathrm{B}} / \mathrm{W}_{\mathrm{A}} \cdot 100$

Where f-Friability, WA-Initial weight (g), WB-Final weight (g)

Tablets of friabilities under $1 \%$ are acceptable.

Measurement of tablet hardness: The crushing strength of tablets was measured by a Monsanto Hardness Tester.

Uniformity of drug content: The test is mandatory for tablets with $10 \mathrm{mg}$ or less weight of active ingredient [21]. Ten randomly selected tablets from each formulation (F1 to F9) were finely powdered and powder equivalent to $4 \mathrm{mg}$ of Perindopril was accurately weighed and transferred to $100 \mathrm{ml}$ volumetric flasks containing $50 \mathrm{ml}$ of $0.1 \mathrm{~N} \mathrm{HCL}$. The flasks were shaken to mix the contents thoroughly. The volume was made up to the mark with $0.1 \mathrm{~N} \mathrm{HCL}$ and filtered. One ml of the filtrate was suitably diluted and Perindopril content was estimated at $215.0 \mathrm{~nm}$ using a double beam UV-visible spectrophotometer.

Wetting time: A piece of tissue paper was folded twice and placed in small petri dish containing $6 \mathrm{ml}$ of phosphate buffer $(\mathrm{pH} \mathrm{6.8)}$ the tablet was placed on it and the time required for complete wetting of tablet was recorded [22].

Water absorption: A piece of tissue paper folded twice was placed in a small petri dish containing $6 \mathrm{ml}$ of water. A tablet was put on the paper and was allowed for complete wetting. The wetted tablet was then weighed Ratio [23]. Water absorption ratio, $\mathrm{R}$, was determined using following equation

$$
\mathrm{R}=\left(\mathrm{W}_{\mathrm{A}}-\mathrm{W}_{\mathrm{B}}\right) / \mathrm{W}_{\mathrm{B}}{ }^{\star} 100
$$

Where, $\mathrm{W}_{\mathrm{B}}$-Weight of tablet before water absorption, $\mathrm{W}_{\mathrm{A}}$-Weight of tablet after water absorption.

\section{In-vitro disintegration time}

In vitro disintegration time (DT) using petri dish method: The in- vitro disintegration time of the orally disintegrating tablets was determined following the procedure described by Gohel et al (2004) [24]. $10 \mathrm{~mL}$ of water at $37^{\circ} \mathrm{C}$ was placed in a petri dish of $10 \mathrm{~cm}$ diameter. The tablet was then carefully positioned in the center of the petri dish and the time required for the tablet to completely disintegrate into fine particles was noted. Measurements were carried out in replicates of three tablet $(n=3)$ and mean were recorded.

In vitro dissolution study: Perindopril erbumine tablet test conditions for the dissolution rate studies were used according USP specifications using USP 24, type I apparatus. The dissolution medium was $900 \mathrm{ml}$ of $0.1 \mathrm{~N} \mathrm{HCl}$. The temperature of the dissolution medium and the rate of agitation were maintained at $37 \pm 0.5^{\circ} \mathrm{C}$ and $50 \mathrm{rpm}$, respectively. Aliquots of $5.0 \mathrm{ml}$ of the dissolution medium were withdrawn at specific time intervals and the volume replaced by fresh dissolution medium, pre-warmed to $37 \pm 0.5^{\circ} \mathrm{C}$. The drug concentration was determined spectrophotometrically at $215 \mathrm{~nm}$ using UV spectrophotometer (shimadzu 1800).

\section{Result and Discussion}

\section{Taste masking of perindopril erbumine by eudragit E100}

The minimum concentration among a range of dilutions to a

\begin{tabular}{|c|c|c|c|c|c|c|}
\hline Sr.no & Formulation & Angle of repose & Bulk density & Tap density & Carr's index & Hausner's ratio \\
\hline 1 & $F_{1}$ & 23.19 & 0.52 & 0.66 & 10.34 & 1.11 \\
\hline 2 & $\mathrm{~F}_{2}$ & 24.10 & 0.5 & 0.62 & 13.79 & 1.16 \\
\hline 3 & $\mathrm{~F}_{3}$ & 24.77 & 0.5 & 0.6 & 20 & 1.25 \\
\hline 4 & $\mathrm{~F}_{4}$ & 25.27 & 0.58 & 0.625 & 10.77 & 1.07 \\
\hline 5 & $\mathrm{~F}_{5}$ & 25.97 & 0.43 & 0.52 & 17.33 & 1.21 \\
\hline 6 & $\mathrm{~F}_{6}$ & 26.56 & 0.47 & 0.57 & 17.48 & 1.21 \\
\hline 7 & $\mathrm{~F}_{7}$ & 29.19 & 0.48 & 0.54 & 12.01 & 1.13 \\
\hline 8 & $\mathrm{~F}_{8}$ & 29.74 & 0.42 & 0.49 & 12.40 & 1.14 \\
\hline 9 & $\mathrm{~F}_{9}$ & 29.93 & 0.361 & 0.40 & 11.59 & 1.13 \\
\hline 10 & $F_{10}$ & 27.82 & 0.37 & 0.44 & 15.08 & 1.17 \\
\hline 11 & $F_{11}$ & 27.89 & 0.45 & 0.54 & 18.51 & 1.22 \\
\hline 12 & $F_{12}$ & 29.05 & 0.44 & 0.57 & 22.8 & 1.30 \\
\hline
\end{tabular}

Table 7: Evaluation of powder characteristics of preliminary batches 
Citation: Ratnaparkhi MP (2012) Formulation and Development of Taste Masked Orally Disintegrating Tablets of Perindopril Erbumine by Direct Compression Method. Pharmaceut Anal Acta 3:162. doi:10.4172/2153-2435.1000162

substance at which the volunteers just start feeling the bitter taste is known as taste threshold concentration. Taste threshold bitterness concentration of Perindopril Erbumine was determined by panel of 12 volunteers and was found to be $110 \mu \mathrm{g} / \mathrm{ml}$. in order to mask the bitter taste of Perindopril Erbumine taste masked granules of Perindopril Erbumine: Eudragit E100 (1:1to1:7) were prepared by mass extrusion technique. A simplified dissolution test was performed to determine the degree of taste masking of bitter taste of Perindopril Erbumine by Eudragit E100. It was found that the amount of Perindopril Erbumine dissolved from the drug polymer complex within 30 seconds decreased with increased concentration of Eudragit E100. The drug: polymer complex that yielded drug release values just below the taste threshold concentration was considered optimum and was used for taste masking. It was observed that the Perindopril Erbumine complexed with Eudragit E100 in proportion of $1: 3$ showed $D_{30 \text { s }}$ values below $100 \mu \mathrm{g} / \mathrm{ml}$. thus it was concluded that Eudragit E100 in proportion to 1:3 was optimum with respect to masking bitter taste of Perindopril Erbumine.

\section{Characterization of perindopril erbumine-eudragit E100 complex}

The DSC thermograms of Perindopril Erbumine, Eudragit E100 and Perindopril Erbumine:Eudragit E100 complex are shown in figures 1,2 and 3 respectively.

The Dsc thermogram of Perindopril Erbumine shows endothermic peak at $154.38^{\circ} \mathrm{C}$ the thermogram of Perindopril Erbumine complex exhibits a peak at $154.06^{\circ} \mathrm{C}$ which indicates that there is very slight drug polymer interaction.

Perindopril erbumine, Eudragit E 100 and Perindopril erbumine: Eudragit E100 complex were also analysed using FTIR to check the changes in the IR spectra that might occur due to the slight drug polymer interaction as observed during the DSC studies. The IR spectra of Perindopril erbumine, Eudragit E100 and perindopril erbumine:Eudragit E100 complex are shown in figures 4, 5 and 6 respectively.

The spectrum of pure Perindopril Erbumine showed characteristic peaks at 2928, 1730, 1645, 1568 and 1392. The spectra of Perindopril Erbumine:Eudragit E100 complex showed the characteristic bands of both Perindopril Erbumine and Eudragit E100 with the exception of peak at 2928. This indicates the presence of interaction between drug

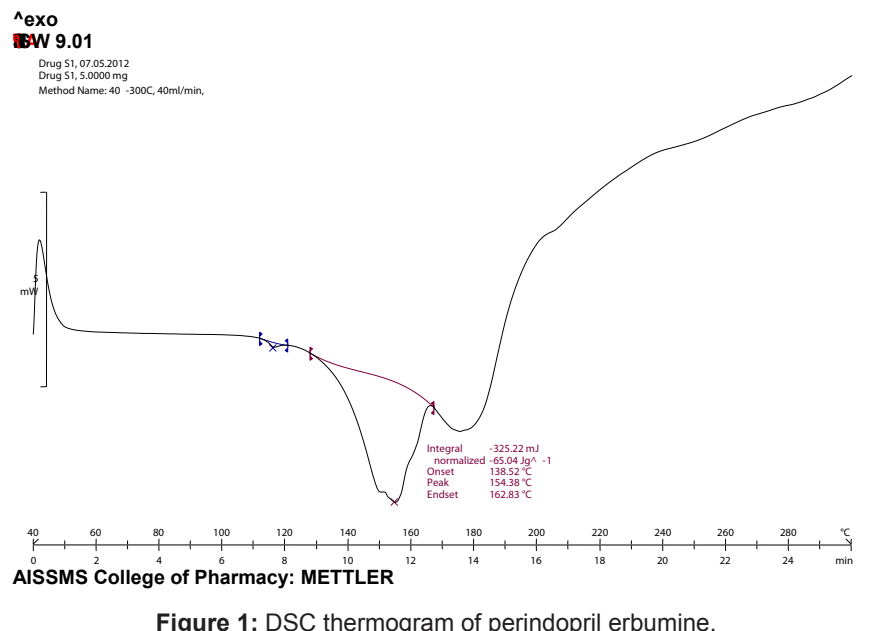

Figure 1: DSC thermogram of perindopril erbumine.
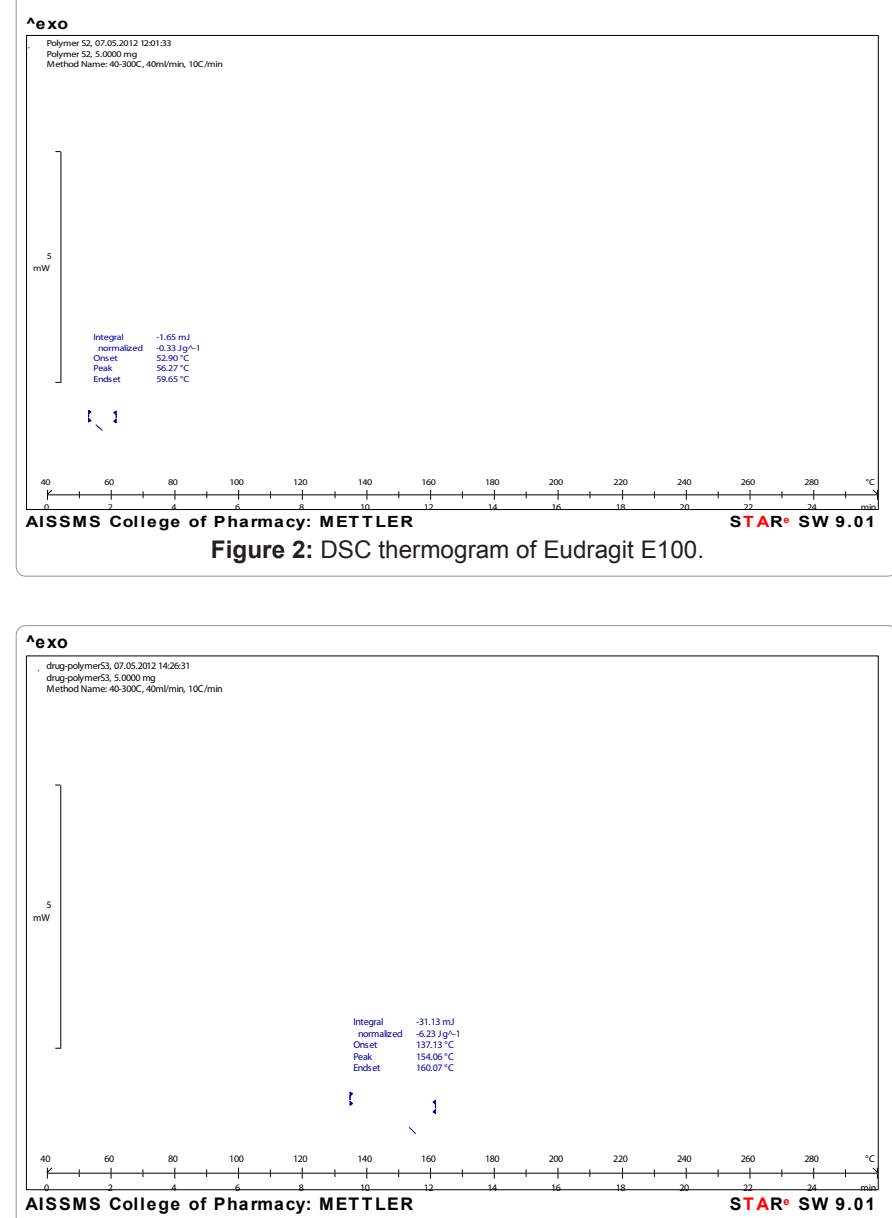

Figure 3: DSC thermogram of perindopril erbumine: Eudragit E100 complex.

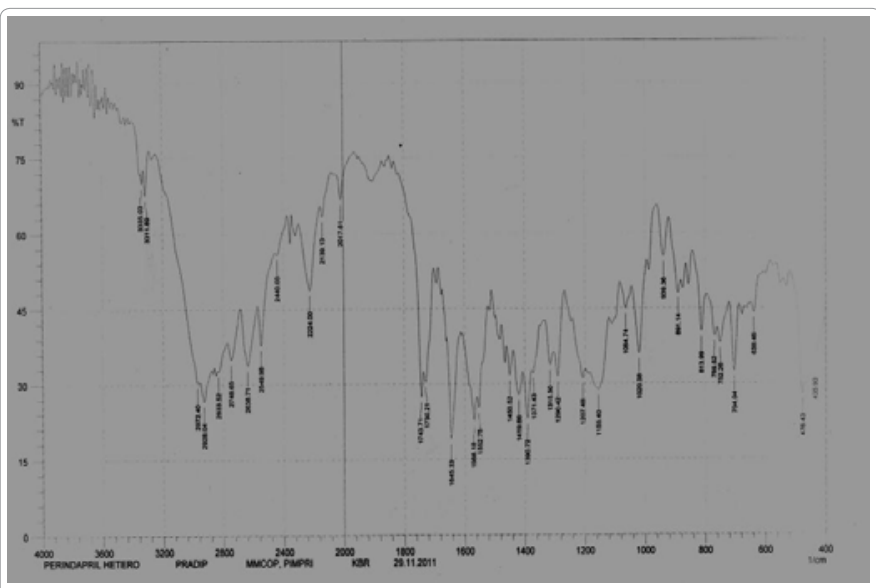

Figure 4: IR spectra of Perindopril erbumine.

and polymer.

The XRD diffraction pattern of Perindopril Erbumine shows sharp peak indicating that the drug is of crystalline nature while that of Eudragit E100 shows blunt peaks indicating its amorphous nature. When crystalline Perindopril Erbumine forms complex with amorphous Eudragit E100 the sharp peak of Perindopril Erbumine disappear. This indicates that the drug forms an apparent amorphous 
state. The change in crystallinity may be the reason for inproved dissolution rate of Perindopril Erbumine when complexed with Eudragit E100. The XRD patterns of Perindopril Erbumine, Eudragit E100 and perindopril erbumine:Eudragit E100 complex are shown in figures 7,8 and 9 respectively.

\section{Preliminary trials}

Characterization of powder flow properties: The powder flow

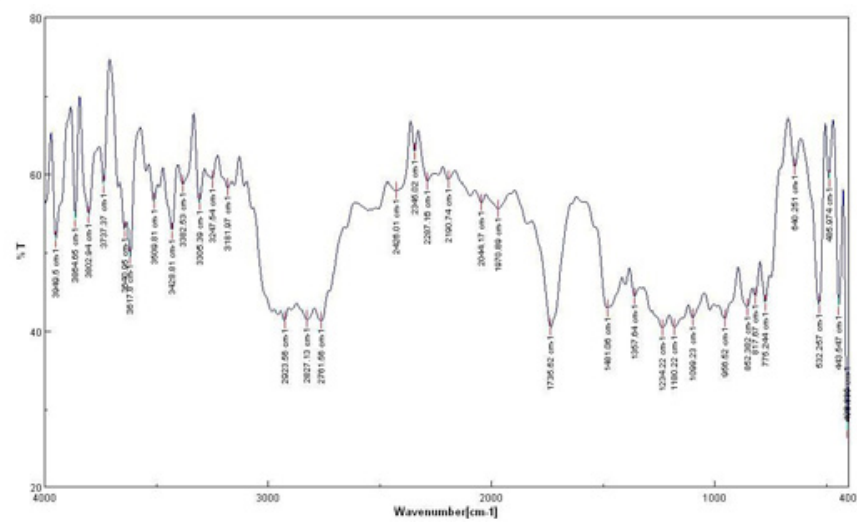

Figure 5: Ir spectra of Eudragit E100.

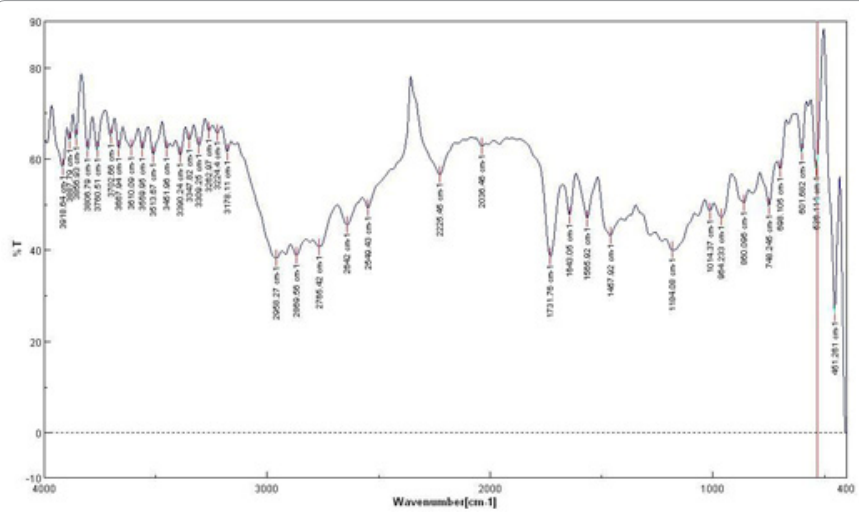

Figure 6: Ir spectra of Perindopril erbumine: Eudragit E100 complex.
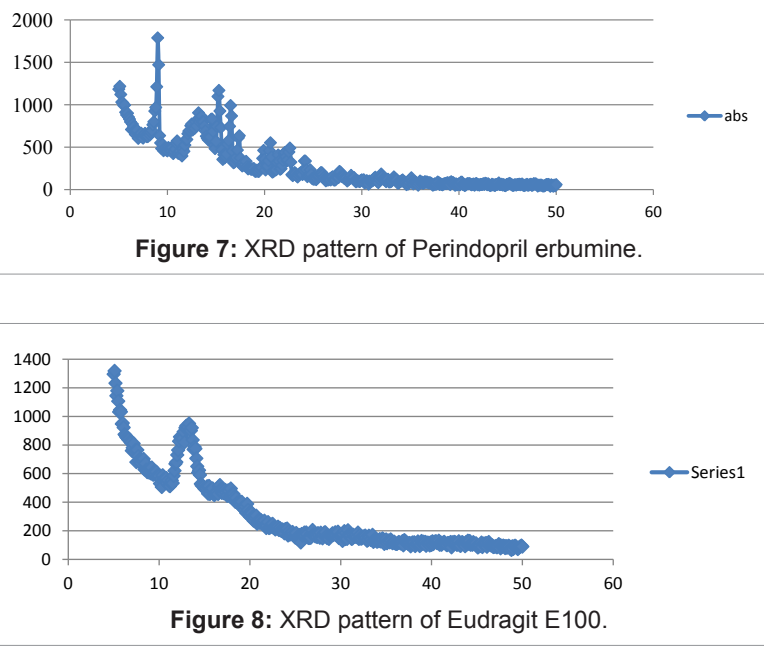

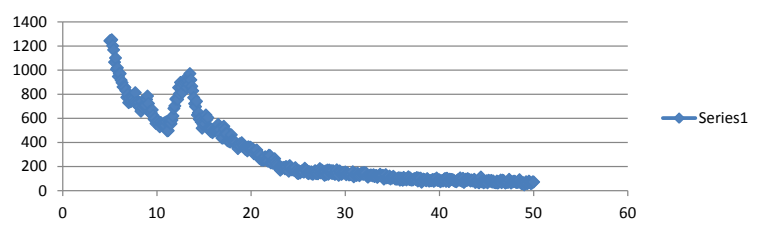

Figure 9: XRD pattern of Perindopril Erbumine: Eudragit E100 complex.

properties were analysed. It was observed that all formulations showed good flow properties with Carr's index ranging from 10.34 to 18.51 and Hausner's ratio below 1.25 which indicated good compressibility and flowability.

Characterization of tablet properties of preliminary batches: Orally disintegrating tablets were prepared by direct compression method. A total of twelve formulations and a control formulation (without superdisintegrant) were prepared using different superdisintegrants described above. All the formulations passed weight variation test. The hardness of all the tablets containing superdisintegrants was found in the range of $3.0-4.2 \mathrm{~kg} / \mathrm{cm}^{2}$. The hardness of control batch was found to be $4.5 \mathrm{~kg} / \mathrm{cm}^{2}$. Friability was found to be below $1 \%$ which was an indication of good resistance of tablets. The results of these evaluation and In-Vitro disintegration time are shown in table 8 .

\section{In-vitro disintegration time}

Various reports have suggested the unsuitability of conventional disintegrating test apparatus when used for testing the disintegration time of orally disintegrating tablets. This is because of extreme operating conditions in the disintegration test apparatus which fail to provide significant discrimination among the orally disintegrating tablets. Furthermore the conventional disintegration test apparatus employs a relatively huge volume of test solution as compared to the volume of saliva present in human buccal cavity. Therefore the results obtained from conventional disintegration test apparatus do not reflect the actual disintegration time; hence in order to get a better response different method of testing the disintegration time was employed. The disintegration time was measured using a petri plate method as described above. It was found that tablets containing 2.5\%, 3.75\% and $5 \%$ of Ac-Di-Sol, 2.5\% and 3.75\% of Primogel, Tulsion-335 and Tulsion 339 showed disintegration time less than that of controlled tablet. However it was observed that tablets containing $5 \%$ of Primogel, Tulsion-335 and Tulsion-339 required more time to disintegrate than the controlled tablet.

The basic principal that governs the action of superdisintegrant Primogel is its extensive swelling which was found to increase with the increasing concentration of Primogel above 3.75\% as the contact of water with Primogel led to formation of viscous plug. Due to increased viscosity with increased concentration of Primogel it was observed that further uptake may be retarded and the tablets break into large particles instead of disintegrating into smaller particles. This might be the reason for increased disintegration time with increased amount of Primogel.

Tulsion-335 and Tulsion-339 are swellable ion exchangers. Tulsion -335 is generally used as taste masking agent but owing to it swelling ability it was considered for the study to check its disintegrating efficiency as a superdisintegrant. It was observed that tablets containing Tulsion-335 and Tulsion-339 showed comparatively larger 
Citation: Ratnaparkhi MP (2012) Formulation and Development of Taste Masked Orally Disintegrating Tablets of Perindopril Erbumine by Direct Compression Method. Pharmaceut Anal Acta 3:162. doi:10.4172/2153-2435.1000162

Page 7 of 10

\begin{tabular}{|c|c|c|c|c|c|c|c|}
\hline Batches & Weight variation & $\begin{array}{l}\text { Hardness } \\
\mathrm{Kg} / \mathrm{cm}^{2}\end{array}$ & $\%$ friability & Wetting time & $\begin{array}{l}\text { Water absorption } \\
\text { ratio }\end{array}$ & $\begin{array}{l}\mathrm{l}-\mathrm{v} \text { i } \mathrm{t} r \mathrm{o} \\
\text { disintegration time }\end{array}$ & $\left.\begin{array}{l}\% \text { drug release }\left(Q_{5}\right. \\
\text { min }\end{array}\right)$ \\
\hline$A_{1}$ & Passes & 3.6 & 0.40 & $85 \pm 2$ & $62.23 \pm 0.046$ & $77 \pm 1.52$ & $100.90 \pm 1.85$ \\
\hline$A_{2}$ & Passes & 3.5 & 0.55 & $63 \pm 2$ & $102.84 \pm 0.752$ & $50 \pm 2$ & $101.29 \pm 1.46$ \\
\hline $\mathrm{A}_{3}$ & Passes & 3.4 & 0.46 & $79 \pm 1.732$ & $77.60 \pm 1.105$ & $70 \pm 1.73$ & $100.40 \pm 0.74$ \\
\hline $\mathrm{A}_{4}$ & Passes & 3.4 & 0.35 & $85 \pm 1.527$ & $68.80 \pm 0.732$ & $72 \pm 2$ & $100.30 \pm 1.84$ \\
\hline$A_{5}$ & Passes & 3.5 & 0.31 & $73 \pm 0.577$ & $98.32 \pm 1.037$ & $64 \pm 2$ & $99.35 \pm 0.70$ \\
\hline$A_{6}$ & Passes & 3.5 & 0.36 & $109 \pm 2$ & $63.40 \pm 1.173$ & $97 \pm 1.52$ & $100.63 \pm 0.65$ \\
\hline$A_{7}$ & Passes & 4.2 & 0.25 & $99 \pm 1.732$ & $60.78 \pm 0.751$ & $89 \pm 2$ & $90.82 \pm 3.03$ \\
\hline$A_{8}$ & Passes & 4.0 & 0.25 & $84 \pm 2$ & $63.83 \pm 0.594$ & $74 \pm 1.52$ & $92.89 \pm 1.19$ \\
\hline$A_{9}$ & Passes & 4.2 & 0.35 & $106 \pm 1.527$ & $57.14 \pm 0.970$ & $97 \pm 1.15$ & $88.90 \pm 2.4$ \\
\hline Control & Passes & 3.8 & 0.40 & $143 \pm 0.711$ & $51.75 \pm 0.242$ & $138 \pm 0.33$ & $72.32 \pm 2.19$ \\
\hline
\end{tabular}

Table 8: Evaluation of post compression parameters of optimized batches.

disintegration time compared to Ac-Di-Sol and Primogel. Furthermore it was also observed that increased concentration of Tulsion-335 as well as Tulsion-339 above $3.75 \%$ caused a longer disintegration time than controlled tablets. This slow disintegration time may be due to the fact that these superdisintegrants have highly crosslinked structures as compared to other superdisintegrants which resulted into longer disintegration time.

It was observed that tablets containing $2.5 \%, 3.75 \%$ and $5 \%$ of Ac-Di-Sol showed lesser disintegration time when compared with the other superdisintegrants at the same concentration levels. AcDi-Sol swells to a larger extent when it comes in contact with water. The fibrous nature of Ac-Di-Sol allows intraparticulate as well as extraparticulate wicking of water at lower concentrations. Ac-Di-Sol is prepared by cross linking of sodium carboxymethyl cellulose, which greatly reduces its water solubility while permitting the material to swell and absorb water several times its mass without losing its fibrous structure. However it was observed that there was a prolongation is disintegration time with concentration of $5 \%$. The reason behind this increased disintegration time may be because of increased viscosity and adhesiveness at higher concentration. As the disintegration time of all batches of tablets containing Ac-Di-Sol showed good disintegration time, it was considered as promising candidate for further studies.

\section{Characterization of powder flow properties of optimized batches}

The powder flow properties of the optimized batches were also studied and from the observations it was concluded that the optimized batches showed good powder flow properties with good compressibility.

\section{Characterization of tablet properties of optimized batches}

Orally disintegrating tablets were prepared by direct compression method. A total of nine optimized formulations were prepared using three different levels of concentration of Avicel PH101 and Ac-Di-Sol described above. All the formulations passed weight variation test and uniformity of content test. The hardness of all the tablets was found in the range of $3.4-4.2 \mathrm{~kg} / \mathrm{cm}^{2}$. Friability was found to be below $1 \%$ which was an indication of good resistance of tablets. It was found that with increase in concentration of Avicel PH101the hardness of tablets increased. Smaller particle size of Avicel PH101 and strong hydrogen bonding between hydroxyl groups due to presence of large number of free hydroxyl groups and thus interaction force at contact points between particles may be a reason for the increased hardness.

\section{Wetting time}

Wetting time was determined for all the nine optimized formulations including the controlled batch it was observed that all formulations showed less wetting time as compared to control batch. It was also observed that the batch $\mathrm{A}_{2}$ showed the wetting time of 63 \pm 2 seconds which was less as compared to other batches. It was also observed that the batches containing 3.75\% of Ac-Di-Sol showed better wetting time as compared to tablets containing $2.5 \%$ and $5 \%$ of AcDi-Sol.

\section{Water absorption ratio}

Water absorption being one of the important steps in disintegration process it was evaluated. It was observed that with increase in water absorption ration the disintegration of tablets was faster as compared to the tablets with low water absorption ratio. It was observed that the tablets containing $3.75 \%$ of Ac-Di-Sol showed highest water absorption ratio of $102.84 \pm 0.752$ which was the highest among all other batches.

\section{In vitro disintegration time}

In-vitro disintegration test was carried out using the method described above. It was observed that the disintegration time of all optimized batches was less as compared to the controlled batch. It was also observed that the disintegration time of batch $\mathrm{A}_{2}$ was the least (50 \pm 2 seconds). Thus it was observed that with lesser concentration of Avicel PH101 upto 15\% and 3.75\% of Ac-Di-Sol tablets with good wetting time, water absorption ratio and lesser disintegration time were obtained figure 10 shows the disintegration of optimized batch $\mathrm{A}_{2}$.

\section{In-vitro dissolution studies}

The drug release of all optimized batches was found to be better than the controlled batch and marketed tablet. The control batch showed $100 \%$ drug release within 15 minutes where-as marketed immediate release tablet of Perindopril Erbumine (Conpae 4) showed 100\% drug 
Citation: Ratnaparkhi MP (2012) Formulation and Development of Taste Masked Orally Disintegrating Tablets of Perindopril Erbumine by Direct Compression Method. Pharmaceut Anal Acta 3:162. doi:10.4172/2153-2435.1000162

release within 25 minutes. It was observed that as the concentration of Avicel PH101 increased the drug release was retarded and the formulations containing very high percentage of Avicel $\mathrm{Ph} 101$ showed $100 \%$ drug release above 5 minutes whereas the batches containing lesser concentration of Avicel PH101 showed maximum drug release within 5 minutes. The graphs showing drug release are given in figures 11-15.

\section{Development of polynomial equation}

From the data of in vitro drug release of factorial formulation $A_{1}$ to $A_{9}$ polynomial equation for in-vitro drug release was derived using design expert 8.0 software. The polynomial equation for $3^{2}$ factorial designs is

$$
\mathrm{Y}=\mathrm{b}_{0}+\mathrm{b}_{1} \mathrm{X}_{1}+\mathrm{b}_{2} \mathrm{X}_{2}+\mathrm{b}_{12} \mathrm{X}_{1} \mathrm{X}_{2}+\mathrm{b}_{11} \mathrm{X}_{1}^{2}+\mathrm{b}_{22} \mathrm{X}_{2}^{2}
$$

Where $\mathrm{Y}$ is the dependent variable, $\mathrm{b}_{0}$ is the arithmetic mean response of nine batches and $b_{1}$ is the estimated coefficient for factor $X_{1}$ The main effects $\mathrm{X}_{1}$ and $\mathrm{X}_{2}$ represent the average result of changing one factor at a time from its low value to high value. The interaction terms

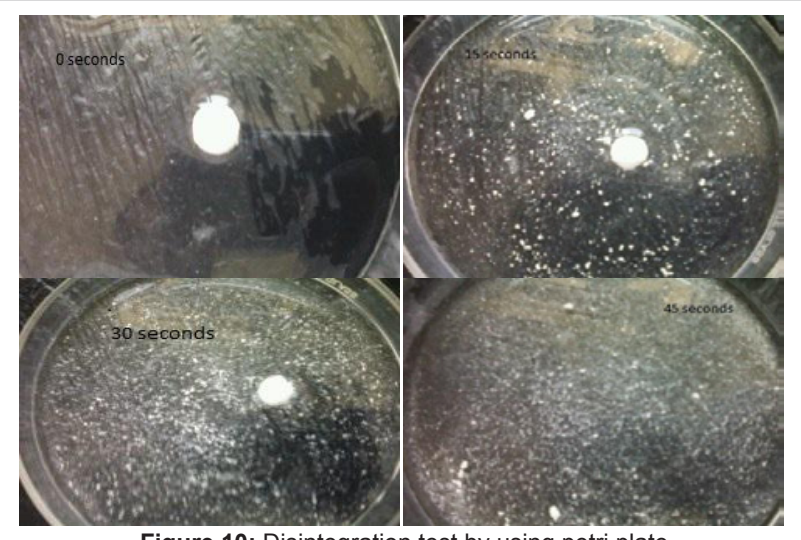

Figure 10: Disintegration test by using petri plate.

$\%$ Drug release of batches $A_{1}-A_{3}$

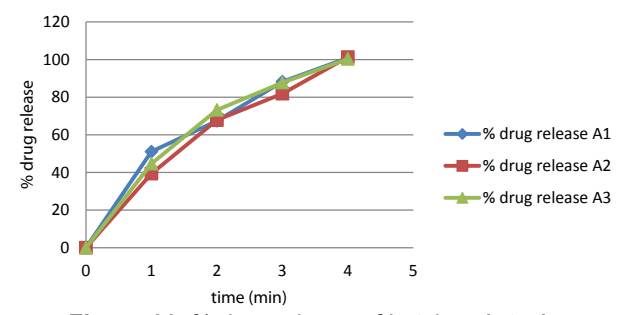

Figure 11: \% drug release of batches $A_{1}$ to $A_{3}$.

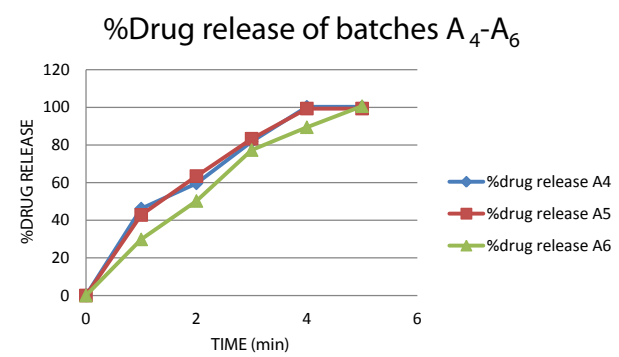

Figure 12: \% drug release of batches $A_{4}$ to $A_{6}$.

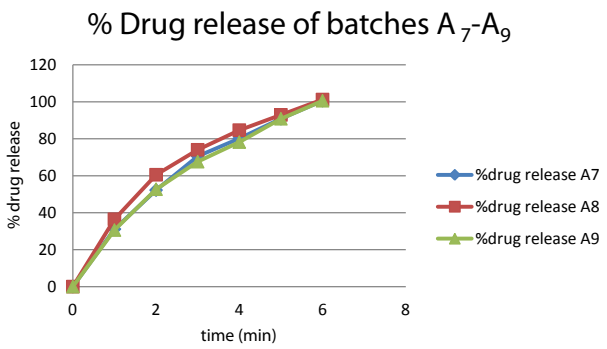

Figure 13: \% drug release of batches $A_{7}$ to $A_{9}$.

\section{\% DRUG RELEASE CONTROL BATCH}

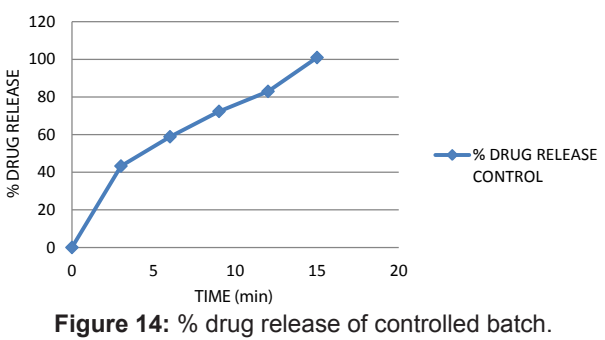

\%Drug release marketed formulation

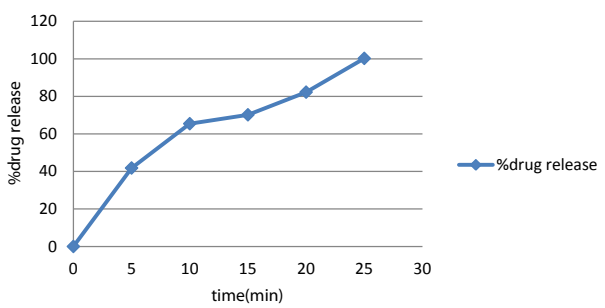

Figure 15: \% drug release of marketed formulation.

$\mathrm{X}_{1} \mathrm{X}_{2}$ shows how response changes when two factors are simultaneously changed. The polynomial terms $\mathrm{X}_{1}^{2}$ and $\mathrm{X}_{2}^{2}$ are included to investigate non linearity.

The $\%$ drug release within 5 minutes for the nine batches $A_{1}$ to $\mathrm{A}_{9}$ showed wide variation from 88.90 to $100 \%$ drug release, thus the data clearly indicated that the \% drug release in 5 minutes is strongly dependent on selected independent variables.

ANOVA showed that the $F$ value of 26.98 implies significant model. There is only $1.07 \%$ chance that the 'model F-value' this large could occur due to noise. Values of prob F less than 0.0500 indicate model terms are significant. In this case the model terms $\mathrm{X}_{1}$ and $\mathrm{X}_{1}^{2}$ are found to be significant. The $\mathrm{R}^{2}$ value of 0.8752 indicates that the model is in reasonable agreement with the adjusted $\mathrm{R}^{2}$ value.

The final equation relating to the response \% drug release in 5 minutes $\left(\mathrm{Q}_{\mathrm{T} 5}\right)$ is given as follows

Coded factors: \% drug release $\left(\mathrm{Q}_{\mathrm{T} 5}\right)=100.53-4.56^{\star} \mathrm{X}_{1}-0.43^{\star} \mathrm{X}_{2}-$ $0.48^{\star} \mathrm{X}_{1} \mathrm{X}_{2}-4.35^{\star} \mathrm{X}_{1}^{2}-1.12^{\star} \mathrm{X}_{2}^{2}$

Actual factors: \% drug release $\left(\mathrm{Q}_{\mathrm{T} 5}\right)=100.53-4.56^{*}$ avicel PH101concentration- $0.43^{\star} \mathrm{Ac}$-Di-Sol concentration $-0.48^{\star}$ avicel $\mathrm{PH} 101^{\star} \mathrm{Ac}$-Di-Sol concentration $-4.35^{\star}$ avicel PH101 concentration ${ }^{2}$ $-1.12^{\star}$ Ac-Di-Sol concentration ${ }^{2}$ 
Citation: Ratnaparkhi MP (2012) Formulation and Development of Taste Masked Orally Disintegrating Tablets of Perindopril Erbumine by Direct Compression Method. Pharmaceut Anal Acta 3:162. doi:10.4172/2153-2435.1000162

Page 9 of 10

\begin{tabular}{|c|c|c|c|c|c|}
\hline Sr.no & Formulation & Weight variation & Friability \% & Hardness $\mathrm{Kg} / \mathrm{cm}^{2}$ & $\begin{array}{l}\text { In-vitro disintegration time } \\
\text { (Sec) }\end{array}$ \\
\hline 1 & $F_{1}$ & Passes & 0.40 & 3.4 & 72 \\
\hline 2 & $\mathrm{~F}_{2}$ & Passes & 0.55 & 3.5 & 64 \\
\hline 3 & $\mathrm{~F}_{3}$ & Passes & 0.46 & 3.5 & 94 \\
\hline 4 & $\mathrm{~F}_{4}$ & Passes & 0.35 & 4.0 & 82 \\
\hline 5 & $\mathrm{~F}_{5}$ & Passes & 0.60 & 3.8 & 79 \\
\hline 6 & $\mathrm{~F}_{6}$ & Passes & 0.55 & 3.5 & 152 \\
\hline 7 & $\mathrm{~F}_{7}$ & Passes & 0.60 & 3.0 & 102 \\
\hline 8 & $\mathrm{~F}_{8}$ & Passes & 0.35 & 3.6 & 117 \\
\hline 9 & $F_{9}$ & Passes & 0.20 & 4.2 & 168 \\
\hline 10 & $F_{10}$ & Passes & 0.55 & 3.4 & 81 \\
\hline 11 & $F_{11}$ & Passes & 0.36 & 3.6 & 124 \\
\hline 12 & $F_{12}$ & Passes & 0.31 & 3.8 & 173 \\
\hline 13 & Control & Passes & 0.40 & 3.8 & 138 \\
\hline
\end{tabular}

Table 9: Evaluation of preliminary batches of fast disintegrating tablets of perindopril erbumine.

\begin{tabular}{|l|l|l|l|l|}
\hline Sr.No & Formulation code & $\mathbf{X}_{1}$ & $\mathbf{X}_{2}$ & Observed values \\
\hline 1 & $\mathrm{~B}_{1}$ & 0.00 & -1.00 & 99.870 \\
\hline 2 & $\mathrm{~B}_{2}$ & -0.89 & 0.31 & 100.058 \\
\hline 3 & $\mathrm{~B}_{3}$ & -0.77 & -0.17 & 100.667 \\
\hline 4 & $\mathrm{~B}_{4}$ & 0.03 & -0.28 & 100.857 \\
\hline 5 & $\mathrm{~B}_{5}$ & -0.01 & -0.45 & 100.019 \\
\hline
\end{tabular}

Table 10: Summary of observed and predicted values of checkpoint batches.

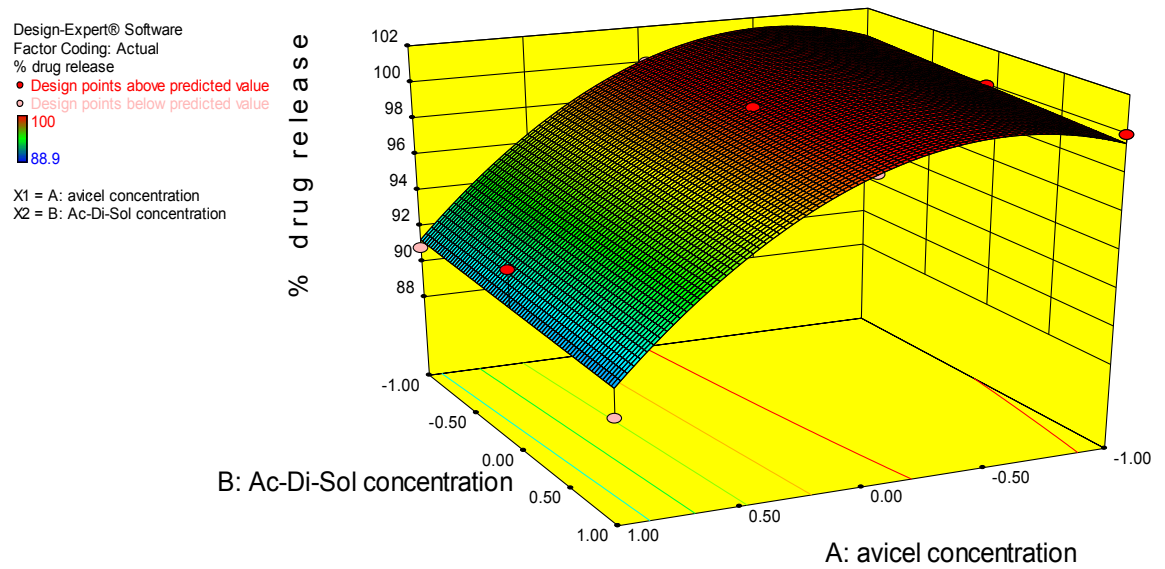

Figure 16: 3D response -surface showing effect of factorial variables on $\%$ drug release.

It was found that the significance level of coefficient $b_{12}$ and $b_{22}$ were found to be $\mathrm{P}=0.4521$ and 0.2507 respectively, hence they were omitted from the full model to generate a reduced model. The final equation for the reduced model was found to be,

Coded factors: \% drug release $\left(\mathrm{Q}_{\mathrm{T} 5}\right)=99.78-4.56^{*} \mathrm{X}_{1}-0.43^{*} \mathrm{X}_{2}-$ $4.35^{\star} \mathrm{X}_{1}^{2}$

Actual factors: \% drug release $\left(\mathrm{Q}_{\mathrm{T} 5}\right)=99.78-4.56^{*}$ avicel PH101concentration- $\quad 0.43^{\star}$ Ac-Di-Sol concentration- $4.35^{\star}$ avicel PH101 concentration ${ }^{2}$.

The negative signs of coefficients $X_{1}$ and $X_{2}$ indicate that as the concentration of binder (Avicel PH101) and superdisintegrant (AcDi-Sol) increases the in-vitro drug release decreases. It can also be observed that with increase in the concentrations of Avicel PH101and Ac-Di-Sol the disintegration time increased.

Validity of the above equation was verified by designing 5 check point formulations $\left(\mathrm{B}_{1}\right.$ to $\mathrm{B}_{5}$ ) and determining the in-vitro \% drug release $\left(\mathrm{Q}_{\mathrm{T} 5}\right)$.

The In-Vitro drug release $\left(\mathrm{Q}_{\mathrm{T}}\right)$ predicted from the equation derived and those observed from the experimental results are summarized in table 9.

The observed values were in close agreement with the predicted values. This proved the validity of the model. The computer generated response surfaces and counter plots for the dependent variables are shown in figures 16 and 17 respectively (Table 10).

\section{Conclusion}

From the evaluations we found that Taste masked oro-dispersible tablet of Perindopril erbumine containing 15\% Avicel PH101 and 3.75\% Ac-Di-Sol gave the best disintegration time and also complete drug release within 5 minutes, it was thus concluded that Eudragit E100 can successfully mask the bitter taste of Perindopril Erbumine in 
Citation: Ratnaparkhi MP (2012) Formulation and Development of Taste Masked Orally Disintegrating Tablets of Perindopril Erbumine by Direct Compression Method. Pharmaceut Anal Acta 3:162. doi:10.4172/2153-2435.1000162

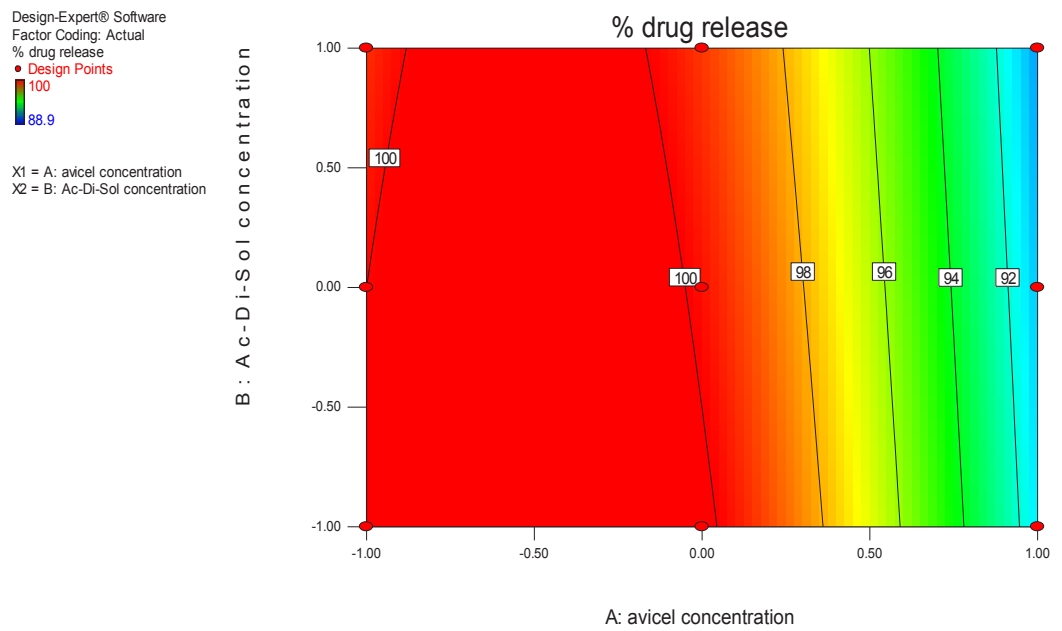

Figure 17: Contour plot showing effect of factorial variable on in-vitro $\%$ drug release.

the ratio of $1: 3$ and orally disintegrating tablets of Perindopril can thus be formed successfully by direct compression method.

\section{References}

1. Sweetman SC (2002) In Martindale: The complete Drug Reference. Pharmaceutical Press London 33: 953.

2. O'Neil MJ, Smith A, Heckelman PE, Kinneary JF (1996) The Merk Index, an Encyclopedia of Chemicals, Drugs and Biologicals. Merck \& Co Inc, White House Station, New Jersey 12: 1234.

3. Hai LZ, Qian C, Wilson YL, Neil GT, Brian T (2003) Perindopril: Along acting angiotensin converting enzyme inhibitor with new clinical trial data. Drug Profile medical progress $40-48$.

4. Sona PS, Muthulingam C (2011) Formulation and evaluation of taste masked orally disintegrating tablets of Diclofenac sodium. Int J Pharm Tech Res 3: 819826.

5. Pravin C, Smita K, Dhananjay M (2011) Formulation development studies of Rizatriptan Benzoate fast disintegrating tablets. RJPBCS 2: 482-496.

6. Dahima R, Sharma R (2010) Formulation and In-Vitro evaluation of taste masked orodispersible tablets of Metoclopramide HCL using Indion. Int J Chem Tech Res 2: 447-453.

7. Rahul VH, Chaudhari PD, Parakh SR, Bauer Brandl (2008) Development of a melting tablet containing Promethazine $\mathrm{HCL}$ against motion sickness. AAPS Pharm Sci Tech 9: 1006-1015.

8. Tatsuya I, Yoshiteru W, Nakoi U, Mitsuo M (1999) Preparation and evaluation of tablets rapidly disintegrating in saliva containing bitter taste -masked granules by compression method. Chem Pharm Bull 47: 1451-1454.

9. Srinivasa RY, Doddayya H, Shrishail SP, Vamshidhar RD (2008) Design and evaluation of fast dissolving tablets of taste masked Ondansetron Hydrochloride. IJPRD 3: 64-76.

10. Satapara RG, Satapara VP (2012) Taste masked oral disintegrating tablets dosage form of Artemether and Lumefantrine. Int J Pharm Res and Dev 4: 86-106.

11. Jyoti S, Meenakshi B (2011) Effects of superdisintegrants in the formulation of taste masked orodispersible tablets of Tizanidine HCL. J Pharm Res 4: 21752178

12. Pawar VK, Sharma G, Garg G, Awasthi R, Kulkarni GT (2010) Taste masking of promethiazine hydrochloride using eudragit e 100 via solid dispersion technique to develop fast disintegrating tablets. Der Pharmacia Lettre 2: 83-94.

13. Marshall KI, Lachman L, Liberman HA, Kanig JL (1987) The Theory and Practice of Industrial Pharmacy, (3rdedn), Varghese publishing house India 66-99.

14. Kakade SM, Mannur VS, Ramani KB, Dahada AA, Naval CV, et al. (2010) Formulation and evaluation of mouth dissolving tablets of losartan potassium by direct compression techniques. Int J Res Pharm Sci 1: 290-295.
15. Swamy PV, Shahidulla SM, Shirsand SB, Hiremath SN, Younus A (2008) Orodispersible tablets of carbamazepine prepared by direct compression method using $3^{2}$ full factorial designs. Dhaka Univ J Pharm Sci 7: 1-5.

16. Ranch KM, Koli AR, Vyas BA, Parikh RK, Vyas RB, et al. (2009) Formulation, design and optimization of orodispersible tablets of Atenolol. Int J Pharm Tech Res 1: 1559-1563.

17. Prajapati BG, Patel DV (2010) Formulation and optimization of domeperidone fast dissolving tablets by wet granulation techniques using factorial design. Int J PharmTech Res 2: 292-299.

18. Shridhar JP, Pasha TY, Bhandari A, Patel JK, Trivedi N, et al. (2011) Design and optimization of taste masked Fexofenadine Hydrochloride resinate by ion exchange resin. Int J Drug Form and Res 2: 134-147.

19. Uniformity of mass of single dose preparations (2004). European pharmacopoeia 233

20. Friability of uncoated tablets (2004). European Pharmacopoeia. (5thedn), Council of Europe, Strasbourg 3103.

21. Uniformity of drug content. Indian Pharmacopoeia vol 2 (4thedn), Controller of publication. Government of India, New Delhi. 1996: 734-736.

22. Yunxia B, Yorinobu Y, Kazumi D, Akinobu O (1996) Preparation and evaluation of oral tablet rapidly dissolving in oral cavity. Chem Pharm Bull 44: 2121-2127.

23. Gohel MC, Bansal G, Bhatt N (2005) Formulation and Evaluation of Orodispersible Taste Masked Tablets of Famotidine. Pharma Bio World 3: 7580.

24. Gohel M, Patel M, Amin A, Agrawal R, Dave R, et al. (2004) Formulation design and optimization of mouth dissolve tablets of nimesulide using vacuum drying technique. AAPS Pharm Sci Tech 5: 10-15. 